Article

\title{
Migrant and Non-Migrant Families in Chengdu, China: Segregated Lives, Segregated Schools
}

\section{Nan $\mathrm{Li}^{1, *}$ and Peggy Placier ${ }^{2}$}

1 Department of Modern Languages, Literatures \& Cultures, Gustavus Adolphus College, Vickner Hall 216, 800 West College Avenue, St. Peter, MN 56082, USA

2 Department of Educational Leadership and Policy Analysis, University of Missouri, Columbia, MO 65211, USA; E-Mail: placierp@missouri.edu

* Author to whom correspondence should be addressed; E-Mail: nli@gustavus.edu; Tel.: +1-507-933-6080.

Academic Editor: Martin J. Bull

Received: 10 December 2014 / Accepted: 24 April 2015 / Published: 5 May 2015

\begin{abstract}
This study documented the experiences of Chinese rural-urban migrant children and their parents living in the host city of Chengdu, China. It was informed by previous studies but applied a theoretical lens cultural reproduction theory-to reveal deeper understanding of rural-urban migrant families' lives in the city of Chengdu. Participants in this study were 10 families - 10 migrant parents, 10 local Chengdu resident parents, 5 local Chengdu children, and 5 migrant children. Through qualitative interviews and observations the researchers created 5 family case studies, documenting differences and similarities in the lives of migrant and local resident families in Chengdu. Results indicated that children in the two groups experienced unequal childhoods. Although the Chinese central government has issued a number of proactive policies to allow migrant children to attend local urban public schools since 2003, the negative effect of the longstanding Hukou residency policy still impacts migrant families' lives in Chengdu. In this article we discuss an entrenched urban-rural divide between urban residents and rural-urban migrant families, in work, community, and schooling.
\end{abstract}

Keywords: Hukou policy; cultural capital; migrant children 


\section{Introduction}

Western researchers have employed cultural capital, a central concept in cultural reproduction theory, to explain how the knowledge afforded by children's home lives affects their educational achievement and attainment. In this study, we used a multiple comparison case study design to examine the cultural capital available to children from two groups of families in Chengdu, ChinaChinese rural-urban migrants and local urban residents - as well as parents' perspectives on their children's educational opportunities and likely futures. This study addressed the following questions:

- What forms does "cultural capital" take and how does it influence the lives of rural-urban migrant children and local urban children living in Chengdu?

- What factors influence migrant families' decisions to send their children to school in Chengdu? In contrast, what factors do local urban families take into consideration when they send their children to school?

Before describing the conceptual framework and design of the study, the following section provides a brief background on the importance of rural and urban identities in China.

\section{Background}

While China was historically known as a predominantly rural nation, free market economic restructuring in recent years has led to widespread rural-urban migration. Between 1980 and 2000, 268 million Chinese migrated from their rural hometowns to urban areas for economic opportunities [1]. While before the 1970 s only about $20 \%$ of the Chinese population lived in urban areas, according to National Bureau of Statistics of China data released in 2001, this had increased to 36\% [2]. Ten years later, the same Bureau reported that close to half (49.7\%) of the population resided in urban areas. China's National Development and Reform Commission indicated that as of November 2008, rural-urban migrants accounted for $47 \%$ of China's population with rural identities [3]. That is, many new urbanites were still officially categorized as "rural".

Under the Hukou system adopted in 1958, Chinese citizens are divided into two hereditary groups: urban residents (those born into households registered in urban areas) and peasants (those born and registered in rural districts). Before the 1980s, the Hukou policy required Chinese citizens to stay in their places of origin. The central government's original purpose for the Hukou policy was to restrict rural-to-urban migration to promote social stability. The policy was explicitly anti-urbanization, and this was a major reason for the high proportion of rural residents before 1980 [4].

As demands for industrial, construction, and service workers grew in the cities, enforcement of Hukou restrictions on urban migration became more lax. Nevertheless, a rural Hukou could still be used as mechanism for social control and restriction of migrants. They might reside in the city, but they did not belong to the city. Migrant workers are called Nongmin gong (farmers-turned-workers), which carries a derogatory meaning. Institutional barriers put migrant workers at a disadvantage, making their adaptation to urban life full of challenges and hardships [5]. Migrant workers have been criticized for burdening urban resources and infrastructure and engaging in crime [5-7]. Although migrant workers provide cheap labor to fuel China's urbanization, they have been excluded from many public services that urban governments provide to their residents [8]. These services include education. 
Shaoqing and Shouli outlined three elements that contributed to migrant children's difficulties in gaining access to equal public education in the city [9]. First, under the Hukou policy until recently the local school district's responsibility was to educate only children born in their judicial administration area. However, some public schools raised additional revenue by setting aside a quota of spaces for a small number of migrant children, charging them higher tuition fees. Second, these Jiedu fees (education rental fees in direct translation from Chinese) were too high and often out of migrant families' affordability [10,11]. Third, migrant workers and their children were often excluded by their city peers. Shaoqing and Shouli found a feeling of marginalization and humiliation among a majority of migrant workers and their children [9]. Their marginalized life experiences also influenced their psychological well-being [5].

During the years when public schools charged high Jiedu fees, migrant workers took a self-help approach of building low-cost schools for their children, referred to as "migrant children's schools". Researchers and journalists identified a plethora of problems with the quality and safety of migrant children's schools [12]. As these were private spaces set aside solely for migrant children, local governments were not compelled to ensure school quality comparable to that in the local public schools [13]. This practice also created de facto segregation of migrant students from their urban peers. Wang's case studies in Beijing and Xiamen (a booming coastal city in southern China) indicated that the poor quality and marginal status of private migrant children's schools resulted in reproduction of inequality between migrant children and their urban peers [14].

\section{Recent Studies of Migrant Students}

By the time of this study, limitations on migrant families enrolling their children in urban public schools had eased. However, public schools enrolling large numbers of migrant children were stigmatized with the label of "migrant children's schools" [15]. Recent studies continue to identify Hukou as the root cause of inequality between the schooling of migrant and urban children. In their multivariate analysis of school enrollment of migrant and non-migrant children in Guangdong province, Liang and Chen found that migration had negative effects on children as a consequence of not having a local Hukou [16]. Through semi-structured interviews of 30 migrant families whose children attended a primary school in Beijing, Koo found that family origin (Hukou) determined the types of educational resources available to them and therefore their educational aspirations and goals [17]. A study of migrant youth in Beijing [18] showed that even after the government relaxed the Hukou-based enrollment policy, migrant children suffered discrimination based on their rural origins. Lu and Zhou used linear regression models to measure the assimilation and well-being of migrant children who attended either low quality migrant schools or urban public schools in Beijing [19]. Their research found that migrant children's rural origins limited their access to mainstream educational resources and thus hampered their ability to achieve social integration, despite the fact that Beijing public schools had enrolled migrant children within their temporary residential district in 2008 . The authors further stated that the newly relaxed enrollment policy for migrant children was stymied because migrant families were still asked to pay extra fees and required to submit numerous documents.

Migrant children's education is a topic of study in other nations, although the particular circumstances and identities of migrants vary. Globalization has increased the movement of families 
across national borders and regions, often with negative effects on children [20]. For purposes of this study we reviewed recent studies of within-country migrants rather than international immigrants. In the United States, migrants work in farms, fisheries, or agriculture-related industries, moving to follow the harvest. Mobility disrupts their children's education, and as a consequence they fall behind and often do not graduate from high school. Migrants are also stigmatized as outsiders (perhaps "illegal" or without documentation of citizenship) who differ physically, culturally and linguistically from the majority [21-23]. A study of Gypsy, Roma, and Traveller students in urban schools in the United Kingdom [24] identified the need for educators to develop a more inclusive school culture that would not marginalize migrants. Makarov's study of migrant students in Moscow schools showed that ethnic Russian students responded negatively to non-Russian newcomer students from other regions because of historical cultural tensions [25]. Therefore, the situation of migrant students in China is not completely unique, but it is distinctive because their outsider status is based primarily on an inescapable rural identity institutionalized by the Hukou.

Previous studies of migrants in China tended to analyze aggregate data collected through surveys in China's major cities such as Shanghai and Beijing. To date, there have been no in-depth multiple comparison case studies looking at rural-urban migrant families' sojourn experiences in a medium size city such as Chengdu. Chengdu is a major, growing economic center for Western China. The first author of this article grew up in Chengdu and was indirectly exposed to rural-urban migrant workers' lives through her father's work. As an architect, her father introduced many migrant workers from poor rural regions to Chengdu's construction-site job market. Many of those jobs are temporary, involving moving heavy construction materials, tearing down old concrete buildings, and moving baskets of cement bricks from one construction site to another. Since her childhood, the first author has heard many stories from migrant workers about their sojourns in Chengdu. Often those stories were extremely sad and revealed how they persevered in a new environment where their rural identity set them apart from their local counterparts in Chengdu. Some of them had school-age children, and like their peers migrating to Beijing, they encountered hurdles in finding adequate educational resources in Chengdu. Starting in 2007, the Chengdu government abolished Jiedu fees (education rental fees); however, migrant children still faced many challenges in school and community.

\section{Theoretical Framework}

Our study examines the premises that (1) the Hukou policy, although not as strictly interpreted as in the past, continues to work as an institutional barrier stigmatizing migrant workers as "urban outsiders" (Cheng shi wai lai ren kou in Mandarin) and (2) urban public schools reinforce this rural-urban divide and therefore reproduce inequality. Our inquiry is framed within cultural reproduction theory, particularly the concept of cultural capital.

Cultural capital is a Western social construct identified with French sociologist Pierre Bourdieu. Cultural capital is not money, but in the right social context it can be exchanged for social advantages that lead to higher income. Bourdieu argued that cultural capital exists in three forms [26]. The "embodied form" is reflected in the dispositions of a person's mind and body. A person's intellectual capacity, knowledge, and acquired skills fall into this category. The second form is the "objectified state" referring to material goods such as books, music CDs, calculators, study guides, maps, and/or 
computers. An affluent family is more likely to purchase this kind of cultural capital for their children than a working-class family without the resources or the knowledge of how or why to obtain these materials. The third form of cultural capital exists in the "institutionalized state", including degrees and qualifications acquired through formal education. Kingston concurred with Bourdieu that "schools reflect and are responsive to the cultural orientation of the dominant class" ([27], p. 89). Hence, children from more affluent families are well-prepared before going to school to possess dispositions that are rewarded by schools. In contrast, children from working class or poor families do not possess the cultural capital which fits into the "cultural biases of this institution" ([27], p. 89).

The definition of cultural capital must be constructed carefully to match the knowledge and resources valued in a particular culture. Bourdieu's typology has been shown to transfer to studies of U.S. education, but the U.S. and China are very different societies. In a classic study of U.S. high school students, DiMaggio [28] defined cultural capital as reading literature, visiting art galleries, drawing, photography, arts attendance, and cultivated self-image- "prestigious" cultural practices typical of the Western upper class's lifestyle or taste [29]. Echoing DiMaggio, Robinson and Garnier defined cultural capital as "the kinds of speech patterns, tastes, and interpersonal skills that the educational system rewards with its credentials" ([30], p. 251). In a study of urban U.S. elementary school children, Lamont and Lareau defined cultural capital as "institutionalized, i.e., widely shared, high status cultural signals (attitudes, preferences, formal knowledge, behaviors, goals, and credentials) used for social and cultural exclusions" ([31], p. 156).

Because Lamont and Lareau's more general definition seems adaptable to different social contexts, we adopted it to examine Chinese rural-urban migrant children's lives and experiences in the city of Chengdu, China. For example, the "social and cultural exclusions" of Lamont and Lareau's definition are evident in educators' unwillingness to admit migrant children to urban public schools because they are viewed as less prepared for school. They may lack English and computer skills, two skills valued by Chinese public schools and society that separate wage-earning workers from well-paid, college-educated professionals and government employees. In China, education (e.g., a college degree or other professional training credentials) has been long thought to be pivotal for individuals' social mobility. By preventing migrant children from entering better quality urban schools, institutions are keeping migrant children from obtaining educational resources essential for their future career advancement. Meanwhile, urban children who already possess "cultural capital" endorsed by schools have advantages based on the institutionalization of "criteria of evaluation" set arbitrarily by urban public schools or exclusive private schools [32].

A limited number of studies of Chinese education have used the concept of cultural capital to examine emerging class stratification in Chinese society. Wang et al. made the first empirical attempt to use cultural capital to study social stratification in Chinese urban society [33]. The researchers conducted a quantitative study interviewing four hundred couples living in China's four major cities. They conceptualized cultural capital as book-reading habits as measured by genres of the books and names of literary authors, finding that education and social class (gauged by skill and occupation) significantly impacted book reading habits and cultural taste. Working-class people were less actively engaged in book reading. Therefore, the authors concluded that current Chinese society is divided by different patterns of cultural consumption that partially define the boundary of social classes. The study was limited in that it identified a static state/pattern of cultural capital distributed among certain 
social classes but failed to explain how book reading habits helped or hindered one's achievement of social mobility.

A study by Koo, Ming \& Tsang interviewed 30 "return" middle school migrant students ("return" means migrant children who move back to their rural hometown after living in a city for a number of years with their parents) to analyze how they utilized and activated educational resources gained in Beijing in their rural hometown in Hebei province [34]. Their findings indicated that cultural capital acquired in Beijing did not benefit the students in rural schools. This finding is consistent with cultural capital theory, because cultural capital can be exchanged for social or educational advantages only in the context ("field of practice" in Bourdieu's terms) in which it is valued by the dominant group. In a mixed-methods study Sheng used cultural capital to examine differences in expectations for higher education in urban China [35]. These expectations differed by social class in interesting ways. Middle class parents hoped that higher education would enhance their children's acquisition of cultural capital and social status. Working class parents hoped their children would attend universities, but were more concerned about economic than cultural factors.

\section{Research Design and Aims}

This research is a multiple comparison case study framed within cultural reproduction theory to explore patterns of migrant families' sojourn experiences in the city of Chengdu, in Sichuan Province of China. Chengdu is a major hub for industry, finance, commerce, and communication in Southwestern China; in the 2010 census the population of the larger metropolitan area approached 15 million. We chose case study as our research design following Yin's definition of case study as "an empirical inquiry that investigates a contemporary phenomenon within its real-life context, especially when the boundaries between phenomenon and context are not clearly evident" ([36], p. 13). We hold that a multiple comparison case study design was the best fit for our research, as we aimed to develop a deeper understanding of Chinese migrant children's sojourn lives (phenomena) in Chengdu (the physical setting). Further, we wanted to compare the cases of migrant children with cases of families who are born in Chengdu. In this way we could investigate the Hukou policy and its lingering effect on Chinese citizens and the Chinese society's emerging class stratification (social context).

We collected data from a sample of five middle-class local Chengdu families and five rural-urban migrant families. A table of the participants' demographic information is attached as the appendix. Each family was composed of mother, father, and at least one child attending public school in Chengdu. We gained access to participants through criterion sampling and theoretical sampling methods [37]. The lead researcher contacted a local construction company's manager in Chengdu by submitting a brief letter informing the manager of her research purpose and the selection criteria. The manager recommended five qualifying families. We chose the participating families via the following criteria: each migrant family's monthly income was below 2500 Yuan (about \$356), both husband and wife were migrant workers employed in Chengdu, and at least one child in the family attended a local public school. We gained access to five local urban families via a convenience sampling procedure based on the lead researcher's social network. The monthly income range for the five local Chengdu participant families varied between 8000 Yuan $(\$ 1143)$ to 12,000 Yuan $(\$ 1713)$. We chose these 
families as our research participants with an intention of comparing their home environments with those of the five migrant families.

Consistent with case study design, the lead researcher used multiple methods to collect data including news reports, semi-structured interviews, field observations, and document (e.g., Hukou policy) analysis. The data reported in this article were generated through individual family interviews and observations of home visits. A semi-structured interview was conducted with each individual family composed of mother, father, and a child in the participants' homes. While the children were present, they were too polite to interrupt adult conversations unless prompted, and then their responses were brief. The interview was conducted in Chengdu city, China. The Sichuan dialect of Chinese language (the participants' home language) was used for the interview. All interviews were audio-recorded. The interview conversations were translated and transcribed immediately following each interview. Each interview lasted between 40 minutes to one hour. In addition to the interviews, field notes of home visits served as a way of comparing the physical home environments of these two groups of participants.

Data analysis borrowed a grounded theory approach to qualitative data analysis [38], analyzing cases inductively for themes specific to each family. The cases of migrant families included themes not relevant to the local Chengdu families: initial migration experiences full of "Ku" ("hardships" in English), migrants' motivation for migrating to Chengdu, and different school practices in admitting migrant children. Six common themes emerged from all cases in our study. For this article, we selected the themes most relevant to cultural capital as defined by Lamont and Lareau [31].

It is important for qualitative researchers to reflect on their identities and potential biases. As previously noted, the lead researcher is a native of Chengdu and fluent in the local language. Her father, an architect who works with construction companies that employ migrant workers, also has family ties to a rural area. Therefore, the lead researcher was familiar with the issue of rural-urban migration before beginning the study. However, the challenge was to avoid imposing middle-class urban assumptions and values in the interpretation of migrant families' interview responses and home lives. This is a challenge especially relevant to studies of cultural reproduction, because certain forms of cultural capital are more valued by the dominant group and mainstream institutions, but that does not mean that the funds of knowledge possessed by non-dominant groups is without value [39].

\section{Findings}

Themes from the cross-case analysis presented in this article are: (1) the rural-urban divide and (2) school choice and segregation. Together with the data on differences in cultural capital afforded in different homes, the data make a case for unequal childhoods [40]. The findings can be viewed as continuing consequences of the Hukou policy's negative effects on migrant families. That is, even when the government policy is "eased", its effects of labeling, stigmatization, and segregation continue as part of the habitus [41] of a community.

The difference in physical living environments between migrant children and local Chengdu children was evidenced in field observations. All five local Chengdu children lived in spacious privately-owned apartments with an area of at least 100 square meters. In contrast, three of the five migrant children lived in rented apartment units with an area of less than 50 square meters. One migrant child lived with his parents and grandmother in their own apartment unit with an area of 
86 square meters, and another migrant girl lived in a privately-owned apartment with less than 40 square meters. This difference can be explained as a function of family income.

Findings from this study show that sometimes cultural capital has similar meanings for both groups. For example, for both group, cultural capital meant credentials such as a college degree. But at the same time, local Chengdu families knew about and were able to provide forms of cultural capital that would advantage their children in the quest for a college degree; for example, visiting museums, travelling during summer and winter breaks, and participating in at least two extra-curricular activities. Mei and Zhang's daughter Lulu traveled every summer. Last year, Lulu and her classmates went to Singapore for seven days. The summer after the interview, she was planning to visit Xi-an, a well-known ancient city where terracotta army men were unearthed. In contrast, migrant families viewed being able to send their children to the local Chengdu public school within their residential neighborhood as an important way of building up cultural capital. In our study, only one migrant child attended English tutoring classes on Saturday and the other four migrant children did not attend any form of extra-curricular activities that for local Chengdu participant children were must-have items on their daily and weekend schedule.

Generally speaking, migrant workers did not have income that was disposable at will compared to their local Chengdu residents. For example, Yan, a construction site supervisor said that: "It was expensive for me to pay 10 Yuan (\$1.43) per class for my daughter's writing club program" [15]. Yan's daughter Mimi ended up quitting a writing class in the middle although she enjoyed it much. In contrast, Yi, a dentist, told the first author that "paying 50 Yuan (\$7.14) for a half-day outing trip in Chengdu was cheap" [42]. During school breaks, all five local Chengdu children went travelling with either their parents or school teachers. All five migrant children either went back to their rural family hometowns or stayed in their enclave living quarters in Chengdu watching TV and doing homework during the summer break. Travelling was simply not a word in the migrant children's life dictionary.

Having high expectations for their children, local Chengdu participant parents in this study were confident about asking the lead researcher to share her experiences in American universities. Migrant parents, in contrast, were hesitant to ask. Yan, a migrant worker father, after much reassurance timidly asked about the cost of attending graduate school in the United States and how to get accepted. After sharing this information with Yan, the lead researcher asked Yan and his wife whether they wished their daughter Mimi to go to graduate school in the United States someday. The couple laughed and said [15,43]: "We do not know. It costs money. It all depends on her if she has that talent and is able to receive a scholarship." Whereas local Chengdu participant parents in this study seemed to take for granted that they would send their child abroad for study someday.

Similar to Yan's comments on her daughter's future study plan, all the other four migrant families told the first author that they let their children "zi wo guan li" literally translated into English as "it is up to him/her". This reflects Lareau's "accomplishment natural growth" ([40], p. 1) parenting style typically observed among U.S. working-class families. In contrast, “concerted cultivation” ([40], p. 1) such as parents being actively involved in a variety of their children's afterschool programs is a norm for middle-class parenting style. This similar pattern of parenting style found in Lareau's ethnographic study and our case study indicated that cultural capital (in the form of family life/parenting style) can be used to explore educational challenges that Chinese rural-urban migrant children have been encountering. 


\subsection{The Rural-Urban Divide}

In terms of Bourdieu's theory, rural and urban settings can be viewed as two separate "fields of practice" for deploying cultural capital. The knowledge and skills valued in one setting may be deemed to be inferior in the other. In Chengdu, we found an obvious "insiders/us" vs. "outsiders/them" divide between local Chengdu residents and rural-urban migrant workers. Participating local Chengdu residents and migrant workers used "us" and "them" in their conversations, indicating that they did not belong to each other's social circles or see themselves as part of the same community. It is true that migrant workers are allowed to live in host cities temporarily for their work, but when we looked at their living and work environment, we could see that they lived in a completely different social space (habitus) from that of their local Chengdu counterparts.

Most migrant workers' initial jobs in their destination cities were similar in nature in a sense that almost all were labor-intensive, low-skilled and poorly-paid jobs which local urban residents were not willing to take. As Solinger pointed out, the undesirable jobs that migrant workers held in the labor market put them in an inferior position in urban society [7]. At the time of the study, some were running small family-owned businesses. In comparison, local urban residents had more choices by virtue of their credentials (e.g., a college degree is a highly valued cultural capital for one to gain social mobility in modern Chinese society), social networks, and financial support to search for a desirable job. They had families and friends nearby, while migrants had often left their extended families in their rural hometowns. Meanwhile, local Chengdu residents viewed migrant workers as a source of "urban crowdedness" and "intensive job competition" as expressed by the participating local Chengdu families.

Mei, a 41-year-old female personal banker attributed Chengdu's "crowdedness" to migrant workers' large influx to Chengdu. Mei and her husband Zhang worked for a major bank in Chengdu and lived an upper-middle class life. The couple seldom cooked at home. They received free breakfast and lunch at their workplace's dining hall and dined out almost every day at dinner time. They picked up their daughter Lulu on Friday afternoons, and then the entire family would drive to Zhang's mother's house to have a family meal. On Saturdays and Sundays, they either drove to Chengdu's outskirts for a one-day trip, or Mei took Lulu to visit museums, watch movies, go to shopping malls, etc. Mei and Zhang owned two housing properties in Chengdu and one sedan. This sounded like a happy and affluent family. However, the researcher was much surprised when Mei said how much pressure she felt when finding herself surrounded by so many people. According to Mei, migrant workers were the "so many people" who had directly caused Chengdu's "over-crowdedness".

When the researcher asked Mei what she thought about migrant workers' move to Chengdu in recent years, she responded [44]:

I think the development of Chengdu needs those migrant workers but I also feel that a large number of migrant workers coming to the city bring inconvenience to our life. For example, I had a hard time to get on the bus after I am off work around 5:30 p.m. every day. The problem now is not about traffic jam any more but about the fact that there is no way I can get on the bus because there are often at least 5 or 6 layers of people waiting for the bus in the downtown area between 5:30 p.m. and 6:30 p.m. I feel surrounded by people everywhere when I go shopping or dine out. Before, I felt Chengdu was a relaxing leisure 
city, but now I feel it is too crowded and Chengdu becomes a city without convenience. I also feel depressed when seeing so many people around me.

Despite her advantages, Mei seemed distressed by changes in Chengdu. Furthermore, she believed this "crowdedness" was brought by the migrant workers flocking to Chengdu city to seek job opportunities.

Another local Chengdu resident, Hong, worked for Chengdu Grid, a government utility company. She viewed migrant workers as adding competitiveness to the already tight job market in Chengdu. Her husband Gang was an airport shuttle driver. Hong and Gang had a 7-year-old daughter, Lan. The family owned a sedan and a 3-bedroom apartment unit in the Northern part of Chengdu city. As is the typical work schedule of government officials, Hong worked from 9:00 a.m. to 5:00 p.m. Monday to Friday. Gang worked 24 hours per shift. After one shift, he took two days off. Therefore, he worked only ten days each month. The young couple, together with their daughter, lived with Hong's parents, who cooked and did other house chores for the couple while they were at work. In China, it is common to see young married couples living with their aging parents due to expensive urban housing and the couple's busy work schedule. In addition, most Chinese grandparents are happy to live with their married children and enjoy taking care of their grandchild.

Hong and Gang told the first author that at their workplaces, there were many migrant workers, but they never developed friendships with them beyond their working relationship. When asked what they thought of migrant workers in Chengdu, Hong responded [45]:

At work, we have co-workers who are from the nearby countryside areas of Chengdu. Their salary is quite low and just enough for making ends meet, but we purchase health insurance for them. They do not have housing property as we do. I also feel that once migrant workers come to Chengdu, the competition of seeking a job becomes fierce. However, since I already got a job, I really do not care about that much.

Hong's husband Gang added [46]:

Over 60 to 70 percent of the employees in my work place are from outside Chengdu. I get along with them. People in Chengdu are very tolerant of outsiders and we do not discriminate against them. As you know, in Shanghai, people in Shanghai discriminate against migrant workers. We are not like those Shanghainese. Chengdu people are very tolerant...

It was interesting that Hong and Gang emphasized Chengdu people's "tolerance" of migrant workers, but meanwhile Hong thought migrant workers came to the city to grab "their" (local Chengdu residents') rice bowls. Gang's comments on the typical Shanghai residents' discriminatory attitude towards migrant workers were consistent with findings of Feng et al.'s study [47] - the social divide between urban and rural areas in Shanghai may contribute to "the formation of a dual society in urban China" ([47], p. 520).

It was obvious from the findings that Chengdu was also a "dual society"; there was a boundary between local urban residents and migrant workers. Among the five migrant families in the study, none claimed that they had made friends with local Chengdu residents, even those who had lived in the city for a number of years. Ren and Luo migrated to Chengdu in 1993. They ran a clock/watch-repair store in the downtown area. They lived with their two children in a rented two-bedroom apartment unit located in a vegetable and meat market. 
Ren came to Chengdu when he was only seventeen. He learned how to fix watches and clocks from his brother-in-law who had come to Chengdu in 1991. At the age of twenty-one, Ren opened his own clock/watch repair store; he and his wife Luo had run it for almost 13 years. The lead researcher visited the store and found that it was tiny, with an area of about 12 square meters. It seemed that Ren and Luo's hard work generated stable financial resources; otherwise, it would be very difficult to raise two children in an urban area such as Chengdu. Ren and Luo had a fixed work schedule from 9:00 a.m. to 6:00 p.m. every day of the week. Luo indicated that most of their customers were local Chengdu residents. When Luo was asked whether she and her husband made friends with them, she said no. Their relationships were strictly merchant and customer.

Ren and Luo's daughter Bei was a 12 year old 5th grader at Sunflower School scheduled to graduate from elementary school in the September following the study. Asked how she felt about her urban neighbors, Bei responded wittily [48]: "We do not know any urban neighbors here. After we get home, we all close our doors. We do not disturb each other." Bei's mother Luo added later [49]: "Our personalities are easy-going. We do not fight with others for getting our own benefits so we get along with local people."

Both groups of participants described their social segregation in benign terms. Local Chengdu residents used the word "tolerance" to describe how they felt generous about migrant workers' moving to Chengdu. The migrant family used the words "easygoing" and "do not disturb each other" to indicate they really "got along" with their local Chengdu neighbors by not being too demanding. It was obvious that although migrant workers and local Chengdu residents live in the same city, they live life separately in their own circles. This segregation extended to schooling.

\subsection{School Choice and School Segregation}

The second research question asked about factors that influenced both groups of parents' decision for their children's school placement. According to Bourdieu, inequalities pass through a cycle via the education system and other social institutions that determined one's life chances [41]. Bourdieu believed that a dominant social group who possessed valuable cultural capital such as education credentials and were familiar with a widely shared culture of members of a dominant culture used the education system to maintain their advantages. This cultural reproduction model fits current Chinese society's class stratification and the role education plays in contemporary Chinese society. Education has long been thought to be the most important tool for individuals to achieve social mobility according to traditional Chinese cultural values. As in many other nations, the quality of rural schools in China lags far behind that of urban schools. It is safe to say that knowledge acquired in rural schools does not have "market value" for migrant parents and their children when they move to the city. This is simply because knowledge endorsed in urban society is vastly different from what farmers value in rural environments.

Regardless of one's economic and social status, generally speaking, Chinese parents want their children to receive a good education and attend college so that they can secure a stable and well-paid job for their future success. Therefore, in China, being able to receive quality education carries paramount meaning in one's future career development. In other words, one's education credential is equivalent to a pass for achieving social mobility. From this perspective, being able to get access to 
quality education is "cultural capital" in and of itself. Obviously, school is pivotal in disseminating knowledge and ideologies valued by mainstream society.

By the time of this study, the Jiedu fees (education rental fees) were no longer an obstacle to migrant children living in Chengdu who wished to attend urban public schools. According to one migrant worker father participant, starting in 2007 all public elementary schools and middle schools in Chengdu abolished extra tuition fees as long as the family lived in the residential area of their neighborhood school district and was able to show required documents to school. However, our findings indicated that migrant families' school choice was still limited depending on where their living quarter was located and the cost of tuition. In China, according to school district law, if parents wish to send their children to a school outside their residential district, the family has to pay substantial fees called school selection fees. Since migrant families normally do not have extra income, they seldom consider paying extra fees to send their children to a school outside their residential area. $\mathrm{Wu}$ found that Chinese middle class parents, in contrast, were willing and able to pay the school selection fees because they understood the value of the cultural capital their children could access in better schools [50].

However, one migrant mother called Lan chose to send her 9 year old son to a better quality public elementary school with smaller class sizes than his assigned public school (Sunflower School), by paying a one-time out-of-school-district fee of 5000 Yuan (\$714) plus the regular semester tuition fees charged to all local Chengdu children. Interestingly, in comparison to the other migrant parents, Lan had received the most education. She went to high school for one year but was forced to quit school due to poverty. All the other nine migrant worker parents either completed or partially received elementary/middle school education.

Intrigued by Lan's decision, the first author wanted to know why she had made such a choice. After further conversations with her, the researcher realized that her work environment was unique in that all her Chengdu colleagues were highly paid architects or civil engineers. She further told the first author that one of her colleagues convinced her that it was worth much money to buy a beneficial learning environment for her son, as Wu pointed out [50]. No doubt, exposed to such "high status cultural signals" ([31], p. 156), this young migrant mother tried to provide as much as she could to support her son's education. At the end of the interview, she indicated that she was willing to invest as much as possible so long as her son could receive a quality education. In her eyes, a good education is the very commodity of "cultural capital" translated into a well-paid job in the future. As she said [51]: "I hope my son can have a white-collar job in the future, get paid well, and not like me and his dad, we did not have much schooling, so we could only take poorly-paid manual jobs."

Three other migrant families in this study sent their children to Sunflower School, where $90 \%$ of the students were migrant children. The remaining migrant child went to an urban public school near his living quarters. The Sunflower School was located near a vegetable and meat market. Before the market was established, a majority of its students were local urban children. However, after the market was established in the mid-1990s, a large number of migrant workers sought job opportunities in this area and brought their children along. Now Sunflower School had earned the label of "a school for migrant children" (Nongmin gong zidi xiao in Mandarin language).

Feng et al.'s survey found that rural-urban migrant workers in Shanghai were segregated from local urban residents [47]. We found that Sunflower School became segregated because some urban parents 
in Chengdu transferred their children to a different school when their residential school district started enrolling migrant children. With the development of private schools in contemporary China, well-to-do urban residents could choose to avoid "migrant schools" like Sunflower School. As one public school principal called Bin, an urban parent participant in this study, told the first author [52]:

After my school started taking lots of migrant children, many former local urban students in my school chose to transfer to a nearby private school. Without telling me why, I knew they did not want to study with migrant children. This was so obvious. Now the student's body in my school is composed of $80 \%$ migrant children.

Bin further shared with the first author that "those migrant children do not have a good foundation to start school" [52]. Similarly, Xiong's field survey on migrant children's schooling experience in Shanghai indicated that some local Shanghainese parents transferred their children out of "Fucheng Junior High School" (the name of the school where Xiong conducted his field study) when this school started enrolling rural-urban migrant children [53].

Another factor affecting migrant children's schooling was that their parents had to undergo a complex registration process, even at a school within their own neighborhood. One migrant worker mother named Xue shared her "frustrating" experiences in dealing with urban school administrators and residential community officials in Chengdu. Xue said that she was asked by her son's school to show paperwork every fall semester so her son could attend the school without paying extra tuition fees. She viewed this redundant requirement of presenting paperwork to the school every year as the school's deliberate intention of trying to get money from her. In her words [54]:

Dong, my son went to school in the fall of 2008. Since we had purchased a housing unit here in Chengdu, we were granted a Chengdu Hukou, and we did not need to pay any extra tuition fees. Otherwise, we would pay the so-called educational sponsoring fee (Jiaoyu zanzhu fee) to the school. To enroll Dong at Orange Garden School, I have to show three forms of paperwork every year to his teacher: Dong's Hukou book, our housing property purchase proof, and the permanent residential permit issued by Chengdu Police Station. Dong's school asked us to show all three paperwork every year. Their intention is to set up obstacles so if we fail to show this paper proof to them in a single year, they would get big money by charging us extra fees (Jiaoyu zanzhu fee). For example, if your Hukou is not in Chengdu and you are not able to show the permanent residential permit in Chengdu and other relevant paper proof to the school, when you enroll your child in that school, they would charge you an extra tuition fee of up to 20,000Yuan (\$2857). Furthermore, the school would ask you to sign a form indicating that you are willing to pay this extra fee to sponsor the development of the school. But you know actually you have no other choice except for paying the extra fee if you wish to send your child to that particular school.

According to Xue, Orange Garden School was still trying to charge extra tuition fees to migrant students and their families if they failed to provide the school with relevant paper proof. Worthy of mentioning here is that Xue and her families obtained a Chengdu Hukou because they owned an apartment unit in Chengdu. However, ironically, their urban identity acquired through economical capital did not diminish their rural origin in the eyes of Chengdu-born administrators and teachers in 
Orange Garden School. At Orange Garden School, the Hukou still seemed to stand out as a deciding factor influencing enrollment of migrant children.

In contrast, the more segregated Sunflower School seemed to be more open to enrolling migrant children; as long as migrant families could show the required paperwork at the time of enrollment (at the beginning fall semester of Grade 1), the child could attend school for the next consecutive five years (from Grade 1 to Grade 6) without being charged extra tuition fees. Jian, a tofu-business owner and his wife Lian shared that they did not have trouble in enrolling their daughter Li at Sunflower School $[55,56]$ :

When we enrolled our child, we showed three paper proofs to the school: our license of running a business, our work permit, and the social registration number. With the three paper proofs, we were able to send our child to Sunflower School and the tuition fee was charged at the same rate as paid by the local urban families. It was easy for us to go through this process. However, things have started becoming more complicated now... Migrant families need to show 5 proofs: permit for giving birth to a baby, a local labor contract signed in Chengdu, Hukou, a signed agreement between the laborer and the employer, and the permit for living in Chengdu, so all together five proofs. I had my paper work done at my residential neighborhood committee and corresponding government branches years ago...

Echoing Jian's comment on "things have started becoming more complicated now" regarding the enrollment requirement paperwork, other migrant worker participants in this study told the first author that they had experienced obstacles in gaining access to the required paperwork from their temporary residential community committee ( $J u$ Wei Hui in Mandarin). Hai was 35 years old with only four years of elementary school education. Hai and his wife owned a small tea shop near the outskirts of Chengdu. The couple had lived in Chengdu for about eleven years by the time of their interview. Hai shared that starting in fall of 2007, all migrant children living in Chengdu did not need to pay extra tuition fees; however, he was not able to provide the required paper proofs to the school before the school semester started, so he and his wife had paid additional tuition fees for one more semester until they finally gathered all the required paperwork (the entire family's Hukou, his wife's labor contract, and their temporary living permit in Chengdu, etc.) stamped and approved by their neighborhood community committee. Hai further explained that it was a "complicated process" for him and his wife to have their paperwork stamped because he often needed to visit a single office at least two or even three times before he could get things done. According to Hai, it took him one month to have all his paperwork stamped by the multiple offices. Perhaps for migrant workers who have a lower education level and fewer social contacts in the host city, understanding and complying with the government's bureaucratic policies would be a challenge, especially when the government issued new policies regulating their work and life in the host city.

For local Chengdu parents, in contrast, the quality of the school was the most important factor that they took into consideration when it came to school choice for their children. In the current Chinese education system, English skills are highly valued by urban schools either private or public. Urban residents with much knowledge of the urban public school system and steady financial resources often elect to send their children to elite private schools or boarding schools. Four out of five local Chengdu 
families in this study sent their children to elite private schools (the average tuition cost for attending this type of private schools is about 20,000 Yuan/ $\$ 2857$ per academic year).

Tao and Lu, a typical middle-class couple shared why they had decided to send their son Meng to a private English boarding school. "English" here means this school's strength is to provide a quality curriculum in teaching English language as a second language. They said [57,58]:

We wanted Meng to go to North America for study in the future. His aunt lives in Canada working as a lab technician at a public university there. Meng's current school is well-known for English teaching. This boarding school's high school department has a specific class called overseas high school prep program. $90 \%$ of the students in that class go to either Britain or North America to finish up their third-year high school education. We want Meng to take advantage of that opportunity when he enters high school stage in the future...

When asked whether he would like to fulfill his parents' expectation, Meng responded with a smile [59]: "I do not know and it was too early to say". Tao and Lu, like many typical Chinese middle class parents, had already planned their child's future for him.

Convenience is another factor for local Chengdu parents to consider when they make a decision for their children's school placement. For example, one mother sent her daughter to a prestigious public elementary school because that school is well-known for academic rigor and is close to her work place. Having the freedom of choosing a quality school to their liking outside their residential areas, all the five local Chengdu families paid large (ranging from \$1500 to \$3000) one-time school selection fees which normally are beyond migrant families' affordability. One dentist mother paid about 20,000 Yuan (\$2857) to a quality public elementary school as a one-time non-refundable deposit fee for her 7 year old daughter whose residential location was outside that school's attendance district. In summary, with freely disposable income, local Chengdu parents in this study tended to send their children to quality private boarding schools or more exclusive public schools, and they especially avoided sending their children to a school with a high enrollment of migrant children. A majority of migrant families did not exercise much choice when making a decision on their children's school placement due to their limited income and relevant government policy restrictions regulating the enrollment procedure. However, the case of Lan, the migrant mother who chose to send her son to a better school, shows that school choice was also a matter of having knowledge of the alternatives. Migrant children tended to attend a separate school (e.g., Sunflower School in this study) where a majority of the students were rural-urban migrants.

\section{Discussion and Conclusions}

Our case study strengthens the argument that through the continuing effects of the Hukou policy, migrant children and their parents have experienced marginalization in both school and community. The deeply entrenched rural-urban divide exists not only in community but also in school. Xiong conducted a field survey in Shanghai, and his research found that rural-urban migrant children's families could not provide them with adequate cultural capital valued by local urban school; therefore local Shanghainese parents viewed migrant children as less prepared for school and were afraid of letting their children mingling with them [53]. In Xiong's study, migrant children being viewed as 
"inferior" by local Shanghainese residents lent support to the themes identified in our research. The data reveal migrant workers' peripheral position in the host city of Chengdu and how education policies serve to keep their children in that position. Their marginalized status is reflected in crowded living environments and challenges in dealing with the urban public school system when they enroll their children. One of the migrant parents participating in our case study told us that even after they obtained Chengdu Hukou through purchasing an apartment unit in Chengdu, at the beginning of each fall semester, she had to show three required documentations to her son's school in order to secure a seat for him. This finding from our case study is consistent with the concept of "institutional exclusions" ([14], p. 695) created by a local public school in the city of Xiamen where the school established difficult entrance examinations barring a large number of migrant children who wished to study in the school. This "institutional barrier" found in both our and Wang's studies shows clearly how Bourdieu's cultural reproduction model [32] works. Through control of knowledge and setting up the rules of game, schools play an important role in maintaining and enhancing the power and status of a dominant social group.

Wang further argued that migrant children do not possess language and cultural practices which urban public school values [14]; thus, they were easily labeled as "outsiders" ([14], p. 695). Our research findings echoed this finding of the rural-urban divide. For example, throughout all the interviews, migrant families and local urban Chengdu residents participating in our study used "us" and "them" to refer to themselves and the other group. From this "us-them" language pattern, one can easily see that there is a divide between the two groups even they live in the same city of Chengdu.

This rural-urban divide deeply rooted in both community and urban schools is caused by China's notorious Hukou policy. We believe that although the Hukou policy has been relaxed to the point of allowing peasants to migrate from their rural hometowns to urban areas for work, the social divide created by the policy and the stigmatizing label it entails put migrant families in a disadvantaged position in the host city, even after many years of residence. They lack social networks in the urban community, and their children are not fully integrated to the urban public school environment [4]. School segregation, a major theme from our study, finds resonance in Lu and Zhou's quantitative study measuring assimilation and well-being of migrant children in Beijing [19]. The regression analysis in their study showed that among migrant children attending isolated migrant schools, almost $40 \%$ had no or few friends. Their data also showed that children attending migrant children's schools were reported as the most disadvantaged group in terms of psychological well-being. The authors further argued that the poor quality and segregated migrant children's schools kept migrant children at the "bottom of the urban hierarchy" ([19], p. 110).

In the meantime, urban middle class families use their economic, social and cultural capital to avoid enrolling their children in integrated schools including migrant children, thus maintaining their home advantages [40]. As one source observed of urban residents, "Few want their children sharing classes with kids they regard as country bumpkins" [60]. In addition, urban middle-class residents are more often able to afford extracurricular and travel experiences that enrich their children's cultural capital. In current China's urban education system, it is a common practice for urban children to participate in one or even more than two extracurricular programs such as piano lesson, Chinese calligraphy lesson, writing club, English conversation lesson, etc. Schools prefer to enroll students who have participated in these programs and view them as having a "good foundation" or being well-prepared for school. 
Whereas migrant children seldom have the opportunity of participating in these school-favored extracurricular programs, no doubt they are placed in a disadvantaged position and encountered many hurdles such as being required to take special entrance exams before being allowed to enroll [53]. Furthermore, urban public school teachers tend to view migrant children as less prepared for school in comparison to their urban peers [53].

Bourdieu \& Passeron stated that family background played a crucial role in providing educational resources to children [32]. In our study, only one migrant worker received some high school education, the rest barely finished junior middle school. In comparison, nine local Chengdu parents in our study hold a college or an associate degree, and one holds a vocational school training degree in dentistry. Therefore, it is safe to say that urban children who possess cultural capital ("having good foundation") valued by urban school are better able to adapt to school life compared to their rural-urban peers who do not possess cultural capital such as English and computer skills rewarded by dominant ideologies under current Chinese education system.

Despite migrant workers' low education level, throughout our interviews, all migrant worker parents expressed their wish of wanting their children to receive as much education as possible although they could not help with their children's studies. At the same time, the reality is that urban school's general attitude of viewing migrant children as ill-prepared for school brings a devastating effect on their marginalized lives in the host city. In our study, we hold that school is not a value-neutral social institution but rather functions as an essential tool in maintaining and rewarding "high status cultural signals" ([31], p. 156).

The findings of this study are reminiscent of patterns in urban U.S. cities in which schools have become increasingly segregated by race and social class. In our case, rather than "white flight" there is "local urban resident flight" to more exclusive schools, facilitated by school choice. Migrant workers in Chengdu are physically indistinguishable from local Chengdu residents, and share the same cultural and linguistic identity. The longer they live in the cities, the less tied to rural culture they become. But their inherited stigmatization as "rural" or "peasant" remains a barrier to their advancement through schooling and in the workplace. Some researchers have gone so far as to call this an "apartheid" system [4]. In a nation in which access to higher education and professional positions is highly competitive, denial of equal education and other social services to the masses of rural migrants is explicitly reproductive. Relaxation of the Hukou policy to allow movement to urban areas has not led to substantial growth of the urban middle class, because most migrants' opportunities for upward mobility through education are blocked by the high cost of quality schools, whether public or private [61].

While there have been repeated calls for reform of this system, the prospect of providing equal services and rights to all residents is daunting [4]. Even if reforms were implemented, they seem unlikely to close the urban-rural divide any time soon. The state would not only have to equalize the quality of public schools but also provide migrant students with access to extracurricular activities - an essential part of cultural capital valued by urban school system. Under market-driven reforms the private schooling sector is likely to continue to flourish as an "escape route" for wealthy parents.

This study is a multiple comparison case study and is not designed to make generalized conclusions regarding all rural-urban migrant families' life situations in a city such as Chengdu, with a population of 2.16 million officially-registered migrant workers as in the year of 2008 [62]. All ten migrant worker participants in this study came from poor rural areas near Chengdu prior to their migration to 
the city. Due to the convenience sampling procedure in recruiting local Chengdu participants, all five local families have middle-class income. We are aware that our sample of the local participants has the limitations of convenience selection and homogeneity. Therefore, future quantitative studies of controlling both groups' income level may be used as a research strategy to evaluate to what degree cultural capital plays its role in maintaining and reinforcing class stratification. Meanwhile, one must be aware that economic capital and cultural capital often interact with each other in many facets of educational studies.

\section{Acknowledgments}

The authors would like to thank the three anonymous reviewers for their constructive comments on the manuscript. We are especially grateful for Faculty Writing Programs generously sponsored by Kendall Center for Engaged Learning affiliated to Gustavus Adolphus College.

\section{Author Contributions}

Both authors participated in the study design and wrote the manuscript. Nan Li performed the field work in Chengdu, China, and analyzed the data.

\section{Appendix}

Table A1. Characteristics of participants.

\begin{tabular}{|c|c|c|c|c|c|}
\hline $\begin{array}{c}\text { Parents * } \\
\text { (Mother/Father) }\end{array}$ & $\begin{array}{c}\text { Ages } \\
\text { (Wife/Husband) }\end{array}$ & $\begin{array}{c}\text { Ed. level } \\
\text { (Wife/Husband) }\end{array}$ & $\begin{array}{c}\text { Occupation } \\
\text { (Wife/Husband) }\end{array}$ & $\begin{array}{c}\text { Children: } \\
\text { Ages }\end{array}$ & $\begin{array}{l}\text { Years in } \\
\text { Chengdu }\end{array}$ \\
\hline \multicolumn{6}{|c|}{ Migrants } \\
\hline Luo/Ren & $34 / 34$ & $\begin{array}{l}\text { Elementary school/ } \\
\text { Junior high school }\end{array}$ & $\begin{array}{l}\text { Clock \& watch } \\
\text { repair business } \\
\text { (both) }\end{array}$ & $\begin{array}{c}\text { Son: } 8 \\
\text { Daughter: } \\
12 \\
\end{array}$ & 18 years \\
\hline Xue/Dong & $30 / 37$ & $\begin{array}{l}\text { Junior high } \\
\text { school(both) }\end{array}$ & $\begin{array}{l}\text { Office assistant/ } \\
\text { Construction } \\
\text { supervisor }\end{array}$ & Son: 9 & 13 years \\
\hline Lian/Jian & $46 / 47$ & $\begin{array}{l}\text { Elementary school/ } \\
\text { Junior high school }\end{array}$ & $\begin{array}{l}\text { Tofu \& soybean } \\
\text { products (both) }\end{array}$ & $\begin{array}{l}\text { Daughters: } \\
24 \& 13 \\
\end{array}$ & 17 years \\
\hline Lan/Tang & $35 / 36$ & $\begin{array}{l}\text { Some high school } \\
\text { education/ } \\
\text { junior high school }\end{array}$ & Chef/Electrician & Son: 10 & 16 years \\
\hline Cui/Yan & $37 / 40$ & $\begin{array}{l}\text { Elementary school/ } \\
\text { Junior high school }\end{array}$ & $\begin{array}{l}\text { Janitor/Constructi } \\
\text { on supervisor }\end{array}$ & $\begin{array}{l}\text { Daughter: } \\
9\end{array}$ & 15 years \\
\hline
\end{tabular}


Table A1. Cont.

\begin{tabular}{cccccc}
\hline $\begin{array}{c}\text { Parents * } \\
\text { (Mother/Father) }\end{array}$ & $\begin{array}{c}\text { Ages } \\
\text { (Wife/Husband) }\end{array}$ & $\begin{array}{c}\text { Ed. level } \\
\text { (Wife/Husband) }\end{array}$ & $\begin{array}{c}\text { Occupation } \\
\text { (Wife/Husband) }\end{array}$ & $\begin{array}{c}\text { Children: } \\
\text { Ages }\end{array}$ & $\begin{array}{c}\text { Years in } \\
\text { Chengdu }\end{array}$ \\
\hline Yi/Wu & $36 / 38$ & $\begin{array}{c}\text { Associate degrees } \\
\text { in dentistry (both) }\end{array}$ & Dentists (both) & Daughter: 10 & $\begin{array}{c}\text { Urban } \\
\text { residents }\end{array}$ \\
\hline Hong/Gang & $37 / 37$ & $\begin{array}{c}\text { College/ } \\
\text { Associate degree }\end{array}$ & $\begin{array}{c}\text { Oxfice } \\
\text { exutive/Airline } \\
\text { shuttle driver }\end{array}$ & Daughter: 7 & $\begin{array}{c}\text { Urban } \\
\text { residents }\end{array}$ \\
\hline Ping/Bin & $39 / 40$ & $\begin{array}{c}\text { Associate degree/ } \\
\text { College degree }\end{array}$ & $\begin{array}{c}\text { Accountant/School } \\
\text { principal }\end{array}$ & Son: 12 & $\begin{array}{c}\text { Urban } \\
\text { residents }\end{array}$ \\
\hline Mei/Zhang & $40 / 41$ & $\begin{array}{c}\text { Associate degree } \\
\text { (both) }\end{array}$ & $\begin{array}{c}\text { Both of them are } \\
\text { bank executives }\end{array}$ & Daughter: 11 & $\begin{array}{c}\text { Urban } \\
\text { residents }\end{array}$ \\
\hline Lu/Tao & Associate degree \\
(both) & $\begin{array}{c}\text { Accountant/Depart } \\
\text { ment store } \\
\text { warehouse } \\
\text { supervisor }\end{array}$ & Son: 12 & $\begin{array}{c}\text { Urban } \\
\text { residents }\end{array}$ \\
\hline
\end{tabular}

* All names are pseudonyms.

\section{Conflicts of Interest}

The authors declare no conflict of interest.

\section{References}

1. Yusuf, Shahid, and Kaoru Nabeshima. "Optimizing urban development." In China Urbanizes: Consequences, Strategies, and Policies. Edited by Shahid Yusuf and Tony Saich. Washington: The World Bank, 2008, pp. 1-40.

2. National Bureau of Statistics of China. Characteristics of Chinese Rural Migrants: 2000. Beijing: National Bureau of Statistics of China, 2001.

3. Anonymous. "Guanyu mingong huang [Regarding lack of migrant workers in China]." 2010. Available online: http://sy08guangdian.blog.sohu.com/145277284.html (accessed on 11 February 2012).

4. Chan, Kam Wing, and Will Buckingham. "Is China abolishing the Hukou system?" The China Quarterly 195 (2008): 582-606.

5. Wong, Daniel Fu Keung, Chang Ying Li, and He Xue Song. "Rural migrant workers in urban China: Living a marginalised life.” International Journal of Social Welfare 16 (2007): 32-40.

6. Cai, X. "Zhonggong nongcun laodongli liudong yu renkou qianyi yanjiu zongshu [Summary of research on rural labor flows and population migration in China]." Nongcun Jingji Yanjiu Cankao 2 (1995): 23-33.

7. Solinger, Dorothy J. Contesting Citizenship in Urban China: Peasant Migrants, the State, and the Logic of the Market. Berkeley: University of California Press, 1999. 
8. Wang, Juchuan. "Thinking about study 'cultural capital' in mainland China." Paper presented at the Annual Meeting of the American Sociological Association, New York, NY, USA, 11 August 2007.

9. Shaoqing, Lu, and Zhang Shouli. "Urban/rural disparity and migrant children's education: An investigation into schools for children of transient workers in Beijing." Chinese Education \& Society 37 (2004): 56-83.

10. Kwong, Julia. "Educating migrant children: Negotiations between the state and civil society." China Quarterly 180 (2004): 1073-88.

11. Nielsen, Ingrid, Berenice Nyland, Chris Nyland, Chris Smyth, and Mingqiong Zhang. "Determinants of school attendance among migrant children: Survey evidence from China's Jiangsu province." Pacific Economic Review 11 (2006): 461-76.

12. Han, Jialing. "Survey report on the state of compulsory education among migrant children in Beijing." Chinese Education and Society 37 (2004): 29-55.

13. Pong, Myra. "State-dominated civil society and migrant children's education in Beijing." IDS Bulletin 45 (2014): 70-82.

14. Wang, Lu. "The marginality of migrant children in the urban Chinese educational system." British Journal of Sociology of Education 29 (2008): 691-703.

15. Yan (pseudonym). Chengdu, China. Interview, 2010.

16. Liang, Zai, and Yiu Por Chen. "The educational consequences of migration for children in China." Social Science Research 36 (2007): 28-47.

17. Koo, Anita. "Is there any chance to get ahead? Education aspirations and expectations of migrant families in China." British Journal of Sociology of Education 33 (2012): 547-64.

18. Kwong, Julia. "Education and identity: The marginalisation of migrant youths in Beijing." Journal of Youth Studies 14 (2011): 871-83.

19. Lu, Yao, and Hao Zhou. "Academic achievement and loneliness of migrant children in China: School segregation and segmented assimilation." Comparative Education Review 57 (2013): 85-116.

20. Hess, Julia Meredith, and Dianna Shandy. "Kids at the crossroads: Global childhood and the state." Anthropological Quarterly 81 (2008): 765-76.

21. Cobb-Clark, Deborah A., Mathias Sinning, and Steven Stilman. "Migrant youths' educational achievement: The role of institutions." Annals of the American Academy of Political and Social Science 643 (2012): 18-45.

22. Free, Janese L., Katrin Kriz, and Jenny Konecnik. "Harvesting hardships: Educators' views on the challenges of migrant students and their consequences on education." Children and Youth Services Review 47 (2014): 187-97.

23. Kandel, William, and Grace Kao. "Shifting orientations: How U.S. labor migration affects children's aspirations in Mexican migrant communities.” Social Science Quarterly 81 (2000): 16-32.

24. Bhopal, Kalwant, and Martin Myers. "Gypsy, Roma and Traveller pupils in schools in the UK: Inclusion and 'good practice'." International Journal of Inclusive Education 13 (2009): 299-314.

25. Makarov, Aleksandr I. "The ethnocultural adaptation of children of migrants in the schools of Moscow." Russian Education and Society 54 (2012): 82-94.

26. Bourdieu, Pierre. "The forms of capital." In Handbook of Theory and Research for the Sociology of Education. Edited by John G. Richardson. New York: Greenwood Press, 1986, pp. 46-58. 
27. Kingston, Paul W. "The unfulfilled promise of cultural capital theory." Sociology of Education 74 (2001): 88-99.

28. DiMaggio, Paul. "Cultural capital and school success: The impact of status culture participation on the grades of U.S. high school students." American Sociological Review 47 (1982): 189-201.

29. Lareau, Annette, and Elliot B. Weininger. "Cultural capital in educational research: A critical assessment." Theory and Society 32 (2003): 567-606.

30. Robinson, Robert V., and Maurice A. Garnier. "Class Reproduction among Men and Women in France: Reproduction theory on its home ground." American Journal of Sociology 91 (1985): 250-80.

31. Lamont, Michele, and Annette Lareau. "Cultural capital: Allusions, gaps and glissandos in recent theoretical developments." Sociological Theory 6 (1988): 153-68.

32. Bourdieu, Pierre, and Jean Claude Passeron. Reproduction in Education, Society and Culture. London: Sage Publications, 1977.

33. Wang, Shaoguang, Deborah Davis, and Yanjie Bian. "The uneven distribution of cultural capital: Book reading in urban China." Modern China 32 (2006): 315-48.

34. Koo, Anita, Holly Ming, and Bill Tsang. "The doubly disadvantaged: How return migrant students fail to access and deploy capitals for academic success in rural schools." Sociology 48 (2014): 795-811.

35. Sheng, Xiaoming. "Parental expectations relating to children's higher education in urban China: Cultural capital and social class." Journal of Sociology 50 (2014): 560-76.

36. Yin, Robert K. Case Study Research: Design and Methods, 3rd ed. Thousand Oaks: Sage Publications, 2002.

37. Patton, Michael Q. Qualitative Research and Evaluation Methods. Thousand Oaks: Sage Publications, 2001.

38. Charmaz, Kathy. Constructing Grounded Theory: A Practical Guide through Qualitative Analysis. Thousand Oaks: Sage Publications, 2006.

39. Moll, Luis C., Cathy Amanti, Deborah Neff, and Norma Gonzalez. "Funds of knowledge for teaching: Using a qualitative approach to connect homes and classrooms." Theory into Practice 31 (1992): 132-41.

40. Lareau, Annette. Unequal Childhoods: Class, Race, and Family Life, 1st ed. Berkeley: University of California Press, 2003.

41. Bourdieu, Pierre. Distinction. London: Routledge, 1986.

42. Yi (pseudonym). Chengdu, China. Interview, 2010.

43. Cui (pseudonym). Chengdu, China. Interview, 2010.

44. Mei (pseudonym). Chengdu, China. Interview, 2010.

45. Hong (pseudonym). Chengdu, China. Interview, 2010.

46. Gang (pseudonym). Chengdu, China. Interview, 2010.

47. Feng, Wang, Xuejin Zuo, and Danching Ruan. "Rural migrants in Shanghai: Living under the shadow of socialism." International Migration Review 36 (2002): 520-45.

48. Bei (pseudonym). Chengdu, China. Interview, 2010.

49. Luo (pseudonym). Chengdu, China. Interview, 2010. 
50. Wu, Xiaoxin. "The dynamic role of cultural capital in the competitive school admission process: A Chinese experience." The Australian Educational Researcher 39 (2012): 275-93.

51. Lan (pseudonym). Chengdu, China. Interview, 2010.

52. Bin (pseudonym). Chengdu, China. Interview, 2010.

53. Xiong, Yihan. Urbanization Children-The Identity of Children of Migrant Workers and Political Socialization of Production (Chinese Edition). Shanghai: Shanghai Century Press, 2010.

54. Xue (pseudonym). Chengdu, China. Interview, 2010.

55. Jian (pseudonym). Chengdu, China. Interview, 2010.

56. Lian (pseudonym). Chengdu, China. Interview, 2010.

57. Tao (pseudonym). Chengdu, China. Interview, 2010.

58. Lu (pseudonym). Chengdu, China. Interview, 2010.

59. Meng (pseudonym). Chengdu, China. Interview, 2010.

60. Anonymous. "Migration in China: Invisible and heavy shackles." The Economist, 6 May 2010. Available online: http://www.economist.com/node/16058750/print (accessed on 29 April 2015).

61. Chan, Kam Wing. "Crossing the 50 Percent Population Rubicon: Can China Urbanize to Prosperity?" Eurasian Geography and Economics 53 (2012): 63-86.

62. Zhuang, Ming. "The social support network for rural migrant workers in Chengdu, China: Local governance and civil society in the fight against poverty and exclusion." IDS Bulletin 40 (2009): $41-49$.

(C) 2015 by the authors; licensee MDPI, Basel, Switzerland. This article is an open access article distributed under the terms and conditions of the Creative Commons Attribution license (http://creativecommons.org/licenses/by/4.0/). 